\title{
Rheological Method for Alpha Test Evaluation of Developing Superplasticizers' Performance: Channel Flow Test
}

\author{
Jae Hong Kim, Jin Hyun Lee, Tae Yong Shin, and Jin Young Yoon \\ School of Urban and Environmental Engineering, Ulsan National Institute of Science and Technology, Ulsan 44919, Republic of Korea \\ Correspondence should be addressed to Jae Hong Kim; jaekim@unist.ac.kr
}

Received 5 October 2016; Accepted 19 December 2016; Published 10 January 2017

Academic Editor: Doo-Yeol Yoo

Copyright ( 2017 Jae Hong Kim et al. This is an open access article distributed under the Creative Commons Attribution License, which permits unrestricted use, distribution, and reproduction in any medium, provided the original work is properly cited.

\begin{abstract}
Advance in high-range water-reducing admixture revolutionizes the workability and constructability of conventional vibrated concrete as well as self-consolidating concrete. Its need from construction fields has increased, and consequently a variety of newtype polycarboxylates, base polymers for the admixture, are being formulated in these days. Synthesizing new polymers needs a quick, but reliable, test to evaluate its performance on concrete. The test is also asked for selecting the best applicable brand of them before a test concrete will be mixed. This paper proposes a "channel flow test" and its usage for the purpose. The proposed procedure for the test includes the mix proportion of a test mortar, the test method, and rheological interpretation of the test results.
\end{abstract}

\section{Introduction}

Polycarboxylate- (PCE-) based high-range water-reducing admixture (HRWRA) was firstly introduced by Nippon Shokubai, Inc. (cement dispersant, JP 842,022; S59-018338; 1981), and then it became one of the most important polymers for chemical admixtures [1-3]. The merits of PCE, a raw material for HRWRA, can be found on its superior performance based on steric repulsion and its variability to control the time of its functioning. Changing its polymeric structure, such as trunk chain length and grafts' configuration, allows us to control the degree and speed of its absorption on cement grains, which results in controlling the time-dependent fluidity of cement-based materials.

A variety of polymeric structures have been developed to respond to needs from construction fields. A simple test to evaluate its performance in the middle of development is accordingly required in a polymer-synthesizing lab. Testing its application on concrete mixtures is certainly necessary at the end. The former can be called "alpha test," evaluating it in the producing lab, and the latter is "beta test" to evaluate its final blend with the field materials such as Portland cement and aggregates. A mini slump flow test [3-5] using a Hagerman cone has been widely used for the alpha test, but it has several limitations on considering the aggregate effect and the sensitivity on fluidity [6]. The cone used for the mini slump flow test was originally designed for a thick mortar. Its flow is triggered by dropping the sample using a so-called flow table.

This paper proposes the use of a channel flow test as an alpha test of PCEs. The volume of a sample increases compared to the mini slump flow test, which expects to get a stable measure of the test result. Finding the mix proportion for a test mortar is also one of the important tasks. The fluidity of the test mortar should represent that of concrete to be applied. Finally, a model functions to evaluate the rheological properties based on the results of channel flow test of the test mortar.

\section{Channel Flow Test for a Test Mortar}

2.1. Apparatus. The channel flow test is designed to sensitively measure the enhanced fluidity of a mortar sample. A volume of $100 \mathrm{~mm} \times 100 \mathrm{~mm} \times 100 \mathrm{~mm}$ (its total volume is $1 \mathrm{~L}$ ) of a mortar sample is placed in the cubic space surrounded by a gate and walls, as shown in Figure 1. The higher volume of a sample, compared to the mini slump flow test $(180 \mathrm{~mL})$, increases the reliability of the measurements. Lifting up the gate induces the mortar flow by its self-weight. When the flow stops, the final length of the channel flow and the time to get the final length or $500 \mathrm{~mm}$ approach are measured. The channel guided to one-direction flow gives higher sensitivity 


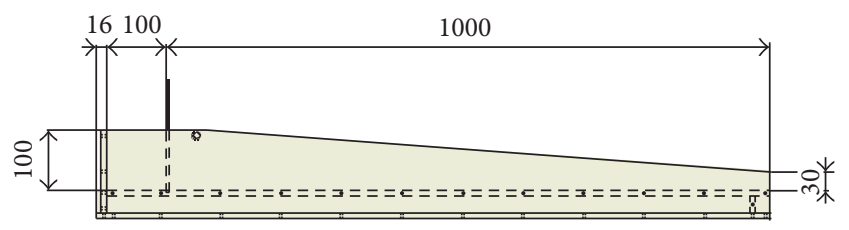

(a)

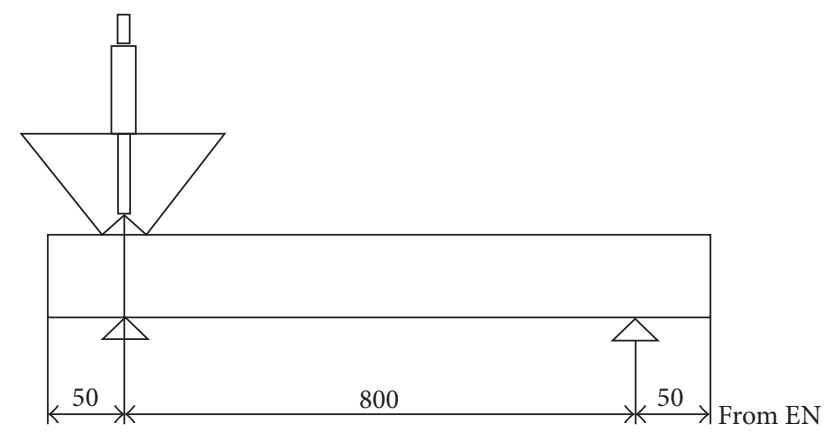

(b)

FIGURE 1: Equipment for (a) channel flow test and (b) grout flow test (dimensions are in $\mathrm{mm}$ ).

than the radial flow by the mini slump flow test. The onedirectional flow is based on the idea of the grout flow test (EN 13395-2. Products and systems for the protection and repair of concrete structures. Test methods. Determination of workability. Test for flow of grout or mortar). While the grout flow test permits the drop of a mortar sample from the charging hopper, a sample in the channel flow test is not subjected to such a dynamic motion. Note that the cross section of the grout flow apparatus is $130 \mathrm{~mm}$ in width by $75 \mathrm{~mm}$ in height and a one liter sample of grout is required for the test.

2.2. Resolution, Sensitivity, and Stability. The prototype of the channel flow test was priorly applied to only indicate the fluidity of mortar samples, where its application was acceptable [7, 8]. More pretests using various cement paste and mortar mixes support the fact that the range of $300 \mathrm{~mm}$ to $700 \mathrm{~mm}$ is acceptable for the channel flow. A sample showing less than $300 \mathrm{~mm}$ channel flow is so thick that it collapses when the gate opens. The collapse of a sample is not wanted to evaluate its flow behavior. On the other hand, a sample showing more than $700 \mathrm{~mm}$ channel flow is susceptible to segregation. Assuming a thin layer is composed at the end of the high channel flow, a sample showing the channel flow of $700 \mathrm{~mm}$ would be $14.3 \mathrm{~mm}$ thick (1 L-volume divided by the planer section $100 \mathrm{~mm} \times 700 \mathrm{~mm}$ ). The front-end thickness is lower than the calculation in practice because the top surface is inclined. Fine aggregates have the maximum grain of $5 \mathrm{~mm}$, which is higher than the one-third of the thin layer thickness. The aggregate segregation is likely to occur in such a case. Note that the effective range of the mini slump flow is considered as $200 \mathrm{~mm}$ to $400 \mathrm{~mm}$ with the same reason.

A resolution test is accomplished in comparison to the mini slump flow test. Figure 2 shows the results of 10 replicated mixes, where two samples were used: one was a neat cement paste prepared by the water-to-cement ratio $(\mathrm{w} / \mathrm{cm})$

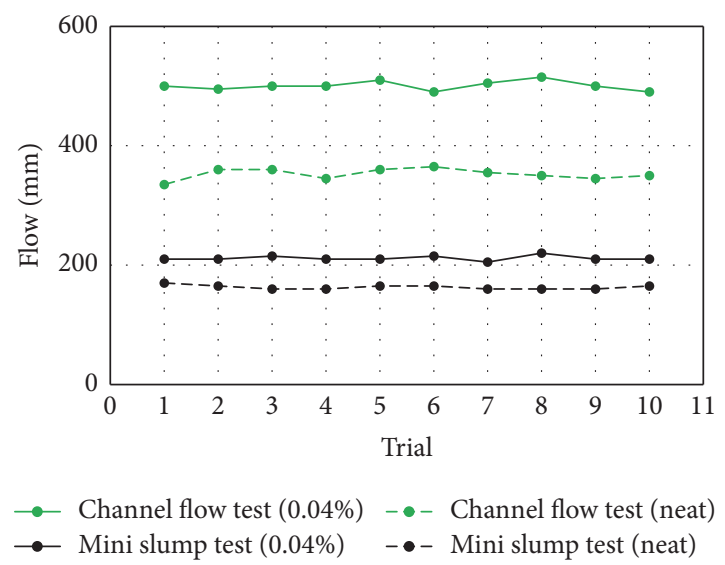

FIGURE 2: The result of resolution and repeatability.

of 0.40 and the other having the same $\mathrm{w} / \mathrm{cm}$ incorporated a HRWRA (0.04\% dosage per cement mass). The superplasticzed cement paste gave the channel flow of $500 \pm 13 \mathrm{~mm}$, which is approximately $\pm 3 \%$ variation on their average. Its mini slump flow was $210 \pm 8 \mathrm{~mm}( \pm 4 \%$ variation approximately). The neat cement paste showed the channel flow of $350 \pm 15 \mathrm{~mm}$ ( $\pm 4 \%$ variation $)$ and the mini slump flow of $165 \pm 5 \mathrm{~mm}$ ( $\pm 3 \%$ variation). On the other hand, comparing the HRWRA effect on both flows indicates the sensitivity of the tests. While the mini slump flow showed $27 \%$ increase in its measurement (from $165 \mathrm{~mm}$ to $210 \mathrm{~mm}$ ), the channel flow did $43 \%$ increase (from $350 \mathrm{~mm}$ to $500 \mathrm{~mm}$ ). Therefore, it can be said that the channel flow test has better sensitivity on the fluidity of a sample and its resolution is in the same range, within $\pm 4 \%$, of the mini slump flow.

The viscosity of a sample is generally related to the time of spreading. One measure to consider the spreading time is the time to get $500 \mathrm{~mm}$ spread, similar to the slump flow test. The other measure for the viscosity evaluation is the time to get the final spread, which showed better correlation on the mini slump flow test [4]. The measuring stability of each time was compared in Figure 3. A total of 4 replicated mixes having $\mathrm{w} / \mathrm{cm}=0.35$ and sand-to-cement ratio of 1.5 by mass were tested. A commercially available HRWRA ( $0.06 \%$ dosage per cement mass) was applied. For a single test, both times for $500 \mathrm{~mm}$ and the final spread were measured together. As can be compared in Figure 3, the times for the final spread and $500 \mathrm{~mm}$ spread showed $10 \mathrm{~s}$ variation $( \pm 22 \%)$ and $3 \mathrm{~s}$ variation $( \pm 23 \%)$, respectively. The value for $500 \mathrm{~mm}$ spread was more stable, even though the resolutions for each of the measurements are similar in percentage. Therefore, the use of the time for $500 \mathrm{~mm}$ spread is recommended because the viscosity is very sensitive to the value of spreading time.

2.3. Rheological Analysis for the Results. Developing a relationship between the rheological properties and the results of a field test allows us to have quantitative understanding on the flow behavior. A theoretical analysis [9] concluded an inverse relationship between the yield stress and the slump flow of a concrete mix. The relationships for the mini slump flow test and marsh cone test were summarized and compared [5], 


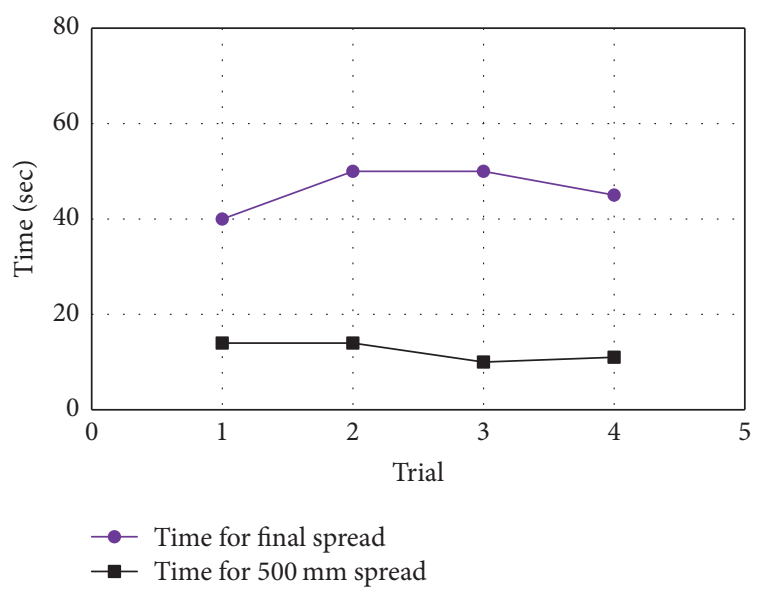

FIGURE 3: Repeatability on the measurement of the spreading time.

where the volume-of-fluid (VOF) simulation was adopted. For example, the yield stress $\left(\tau_{y}\right)$ and the plastic viscosity $\left(\eta_{p}\right)$ can be obtained from the measurement of the mini slump flow test [4]:

$$
\begin{aligned}
\tau_{y} & =0.00660 D_{f}^{-5.81}, \\
\eta_{p} & =\tau_{y}\left(0.00641 T_{f}-0.00194\right),
\end{aligned}
$$

where $D_{f}$ and $T_{f}$ are the mini slump flow, in meter, and the time to get the final mini slump flow, in second, respectively.

The volume-of-fluid (VOF) technique was also applied to simulate the channel flow test. A half-symmetric model was composed with 8 -node hexagonal elements. The average mesh size was $10 \mathrm{~mm}$, which is small enough to have an accuracy in the flow simulation of cement-based materials [10]. Thus, the number of elements was 2,700 for modeling an $800 \mathrm{~mm}$ long channel. The time increment for explicit computation was $0.1 \mathrm{~s}$, and the channel flow was simulated for $65 \mathrm{~s}$. Input variables for the flow simulation were yield stress and plastic viscosity assuming a mortar sample is a Bingham model fluid. Its density was set to $2,200 \mathrm{~kg} / \mathrm{m}^{3}$. Figure 4 shows an example result of flow simulation: (a) snapshots of the VOF simulation and (b) time spread curve for a Bingham fluid having $15 \mathrm{~Pa}$ yield stress $\left(\tau_{y}\right)$ and $30 \mathrm{~Pa} \cdot s$ plastic viscosity $\left(\eta_{p}\right)$. The front of the channel flow was determined by the volume fraction of each element.

In order to establish database of the flow simulation, each spread curve was fitted by a logarithmic function:

$$
C(t)=\alpha+\beta \ln (t)
$$

where $\alpha$ and $\beta$ are the parameters related to the final length of spread and its damping, respectively. As shown in Figure 4(b), the logarithmic function showed a satisfactory fitting than an exponential function. The coefficient of determination was higher than 0.95 for most of spread curves. Assigning a cut-off velocity $\left(V_{f}\right)$ of $1 \mathrm{~mm} / \mathrm{s}$ allows us to catch the time for the Bingham fluid stops: its flow front stops

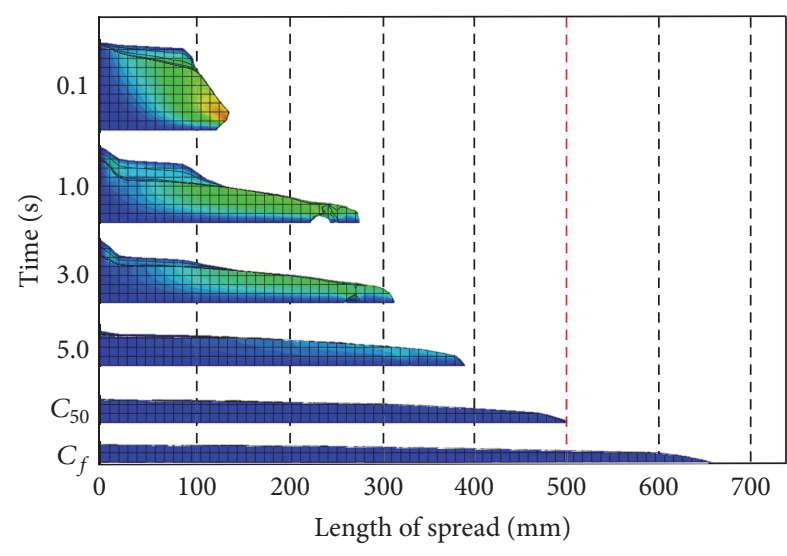

(a)

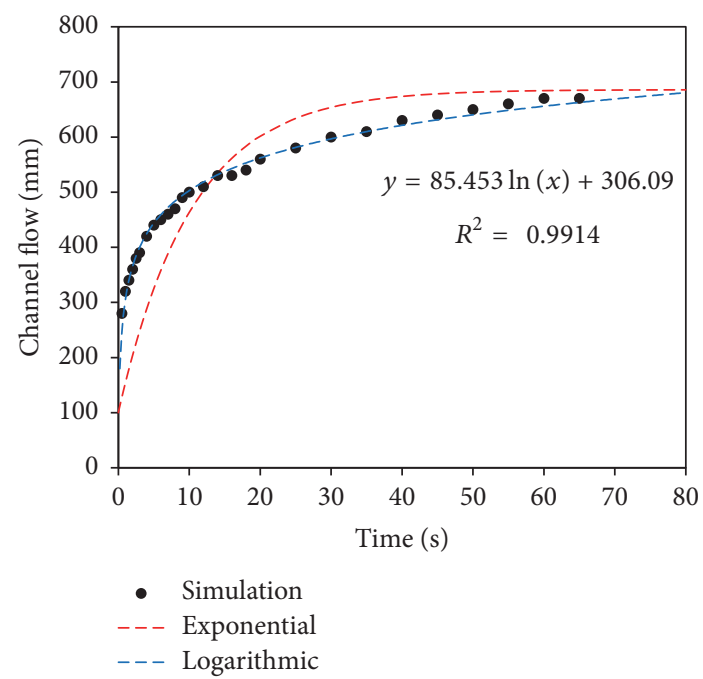

(b)

FIGURE 4: Simulation contour and spread curve of channel flow simulation.

moving at the time of $\beta / V_{f}$ from the derivative of (1). The final spread of the channel flow test is then calculated by

$$
C_{f}=\alpha+\beta \ln \left(\frac{\beta}{V_{f}}\right)
$$

which is a measure of the channel flow $\left(C_{f}\right)$. In addition, the time for its $500 \mathrm{~mm}$ flow is

$$
C_{50}=\exp \left(\frac{500-\alpha}{\beta}\right) .
$$

The flow simulations were conducted for the range of 1 to $60 \mathrm{~Pa}$ yield stress and 0 to $100 \mathrm{~Pa} \cdot \mathrm{s}$ plastic viscosity. A total of 48 combinations were parameterized by (3). Finally, the database composed of $\tau_{y}, \eta_{p}, C_{f}$, and $C_{50}$ developed using (4) and (5).

Figure 5(a) shows the correlation between the rheological properties and the results of the channel flow test. The channel flow $\left(C_{f}\right)$ was inversely proportional to the yield stress of 


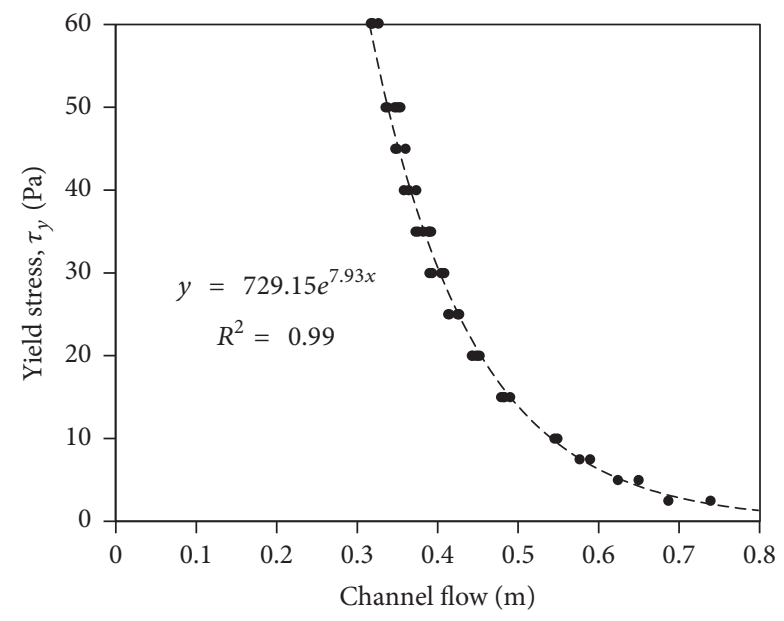

(a)

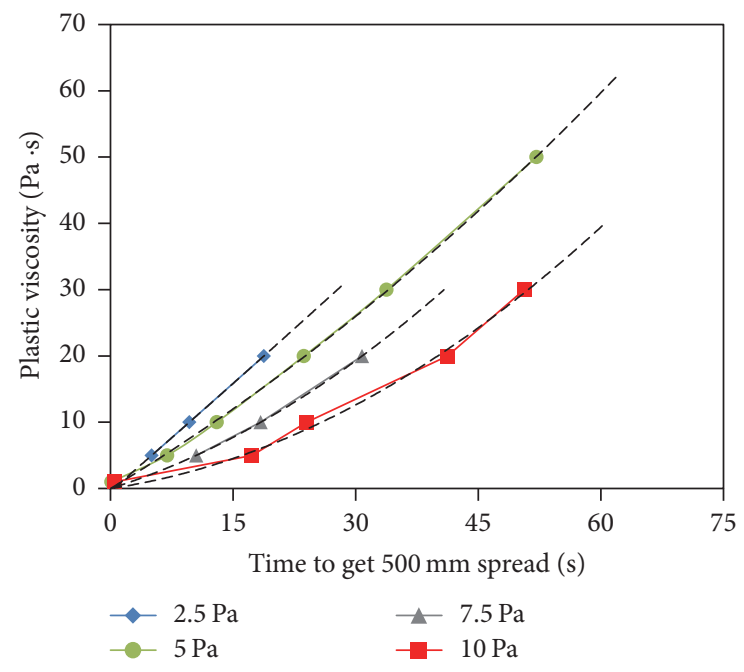

(b)

FIgURE 5: Correlation for the rheological evaluation.

a Bingham fluid, which is similar to the tendency for the slump flow. The inverse proportionality was modeled by

$$
\tau_{y}=k_{1} \exp \left(-\frac{C_{f}}{k_{2}}\right)
$$

where $k_{1}$ and $k_{2}$ are fitting coefficients in the unit of "Pa" and " $\mathrm{mm}$," respectively. Their values determined by a linear regression are listed in Table 1 . In addition, as shown in Figure 5(b), the $500 \mathrm{~mm}$ flow time had a power-law relation with the plastic viscosity when the yield stress is fixed. Encapsulating the effect of the yield stress in the model parameters gave

$$
\eta_{p}=a \cdot\left(\frac{C_{50}}{k_{6}}\right)^{b}
$$

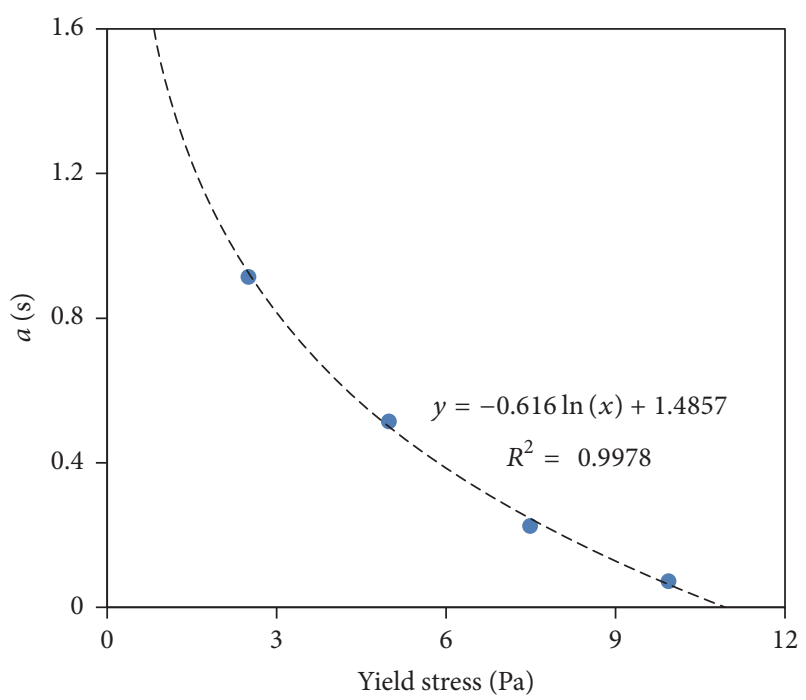

(a)

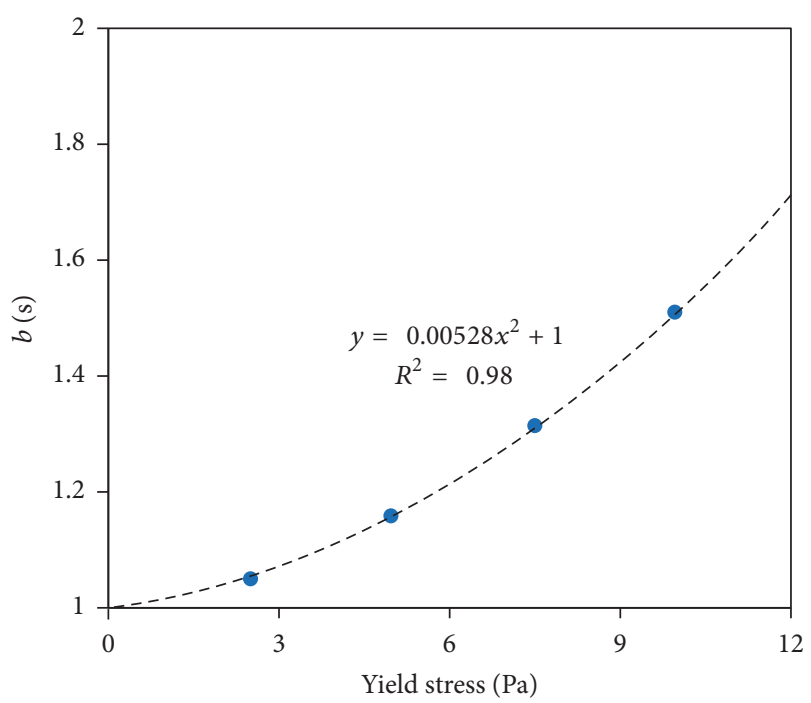

(b)

FIGURE 6: Regression analysis for the model parameters $a$ and $b$.

where $k_{6}$ is a coefficient determining the unit of the plastic viscosity, here in "s." The model parameters, $a$ and $b$, were then functions of the yield stress:

$$
\begin{aligned}
& a=-k_{3} \ln \left(\frac{\tau_{y}}{k_{4}}\right), \\
& b=\left(\frac{\tau_{y}}{k_{5}}\right)^{2}+1,
\end{aligned}
$$

where $a$ and $b$ were dimensionless parameters, and the units of $k_{3}, k_{4}$, and $k_{5}$ were determined to "Pa.s," "Pa," and "Pa," respectively, for nondimensionalization. Excepting the cases having a high yield stress $\left(\tau_{y} \geq 10 \mathrm{~Pa}\right)$, the coefficients of determination were larger than 0.99 for a linear regression with respect to $a$ and $b$. Figure 6 shows the results of the linear regression for the $\eta_{p}-C_{50}$ relationship. The high yield stress cases also follow the trends in (8) with marginal errors. 
TABLE 1: Coefficients for the correlating model.

\begin{tabular}{lcccccccccc}
\hline$k_{1}$ & $k_{2}$ & $k_{3}$ & $k_{4}$ & $k_{5}$ & $k_{6}$ & $k_{7}$ & $k_{8}$ & $k_{9}$ & $k_{10}$ & $k_{11}$ \\
\hline $729 \mathrm{~Pa}$ & $126 \mathrm{~mm}$ & $0.616 \mathrm{~Pa} \cdot \mathrm{s}$ & $11.2 \mathrm{~Pa}$ & $13.8 \mathrm{~Pa}$ & $1.0 \mathrm{~s}$ & $3.0 \mathrm{~s}$ & $1568 \mathrm{~Pa}$ & $46.1 \mathrm{~s}$ & $11.6 \mathrm{~Pa}$ & $1 \mathrm{~Pa} \cdot \mathrm{s}$ \\
\hline
\end{tabular}

In the same way as the $\eta_{p}-C_{50}$ relationship, that for the time to get the final spread $\left(\eta_{p}-C_{t f}\right)$ could be correlated. One may refer to the previous study [11]. Here, the result of the correlation is reported:

$$
\begin{aligned}
\eta_{p} & =k_{11} \exp \left(\frac{C_{t f}-d}{c}\right), \\
c & =-k_{7} \ln \left(\frac{\tau_{y}}{k_{8}}\right), \\
d & =k_{9} \exp \left(\frac{-\tau_{y}}{k_{10}}\right),
\end{aligned}
$$

where the value of each coefficient is listed in Table 1.

2.4. Mix Design of a Test Mortar. PCEs are usually applied for having the fluidity of self-consolidating concrete (SCC), and then a test mortar needs to represent the rheophysical state of SCC. The rheophysical state of a concentrated suspension is usually described by solid volume fraction [12]. Suspension models such as Krieger-Dougherty equation also indicate that the volume fraction of aggregates is critical $[13,14]$. The aggregate volume fraction for SCC is intentionally reduced to decrease its yield stress, and its water-to-cement ratio is also reduced to have better stability. For example, an SCC's mix proportion by mass ratio is given by $0.33: 1: 1.63$ (cementitious binder, water, and fine and coarse aggregates, resp.). The volume fraction of aggregates is $0.65 \mathrm{in}$ the mix. In comparison, normal concrete is proportioned by $0.56: 1: 2.74$ and the volume fraction of aggregates is 0.71 . Finally, the mix proportion for a test mortar is regularized by $0.35: 1: 1.5$ for considering the rheophysical state of SCC.

Using a bag of standard sand (ISO 679. Methods of testing cements. Determination of strength) makes it easy to prepare a sample. The mass of the bag is $1.35 \mathrm{~kg}$, and then those of water and cement become $0.315 \mathrm{~kg}$ and $0.9 \mathrm{~kg}$, respectively. Approximately $1.12 \mathrm{~L}$ of a test mortar is then produced. Note that ISO 679 provides the mix proportion of $0.5: 1: 3$ for measuring the cement strength. The mix proportion for evaluating the PCE effect needs a higher water-to-cement ratio (0.35) and relatively smaller content of sand (1.5).

The optimal procedure to evaluate the performance of PCE is finally established:

(1) A test mortar sample is prepared with the cement-tosand ratio of 1.5 and the water-to-cement ratio of 0.35 . Approximately $1.12 \mathrm{~L}$ will be obtained with $0.315 \mathrm{~kg}$ water, $0.9 \mathrm{~kg}$-cement, and $1.35 \mathrm{~kg}$-standard sand. The dosage of PCE needs to be adjusted to get the channel flow of 300 to $700 \mathrm{~mm}$.

(2) The raw materials are mixed for 5 min using a planetary mixer.
(3) The channel flow test is followed. The final length of spread, $C_{f}$, the time taken for the sample to have $500 \mathrm{~mm}$ spread, $C_{50}$, and the time when the flow stops, $C_{t f}$, are measured.

(4) The channel flow test is repeated at an interval of $30 \mathrm{~min}$, generally for $2 \mathrm{~h}$, where it is important to remix the sample for $1 \mathrm{~min}$ before each repeating measurement. In between the measurements, the loss of water in the sample should be prevented using a plastic cover.

(5) The measured values of $C_{f}$ and $C_{50}$ at $0,0.5,1.0,1.5$, and $2.0 \mathrm{~h}$ are reported. Finally, the yield stress and plastic viscosity of a test mortar can be computed using the correlating equations.

\section{Application}

A total of 6 PCEs were tested. Monomers for their polymerization were the same, acrylic acid and polyethylene oxide. All of them were categorized in the MPEG-type [1]. Their molecular structures, however, varied by different process of polymerization, which results in showing various performance. Following their designed performance, the PCEs were divided into water-reducing type or consistency-maintaining type. The water-reducing PCEs, labeled by LA, LB, and LC, show fast adsorption on cement grains, and then a mix shows high fluidity with a small dosage. In terms of total solid content, a water-reducing PCE was incorporated in $0.12 \%$ of cement mass. The consistency-maintaining PCEs, labeled by LD, LE, and LF, were in $0.16 \%$ of cement mass. They were adsorbed rather slowly and the samples incorporating them show less fluidity.

Table 2 shows the results of the channel flow test accompanied with the mini slump flow test. The channel flow test was applied into the test mortar following the optimal procedure in Section 2.4, but the mini slump flow test was done with a cement paste having the water-to-cement ratio of 0.34 . The dosage for each PCE was the same for both tests.

The channel flows for the water-reducing PCEs were similar to each other at $0 \mathrm{~h}$, and they decreased over time. Only $71 \%, 54 \%$, and $73 \%$ of channel flow of LA12, LB12 and $\mathrm{LC12}$, respectively, were maintained for $2 \mathrm{~h}$. However, the corresponding mini slump flows showed discrepancy: LB12 showed much less fluidity even at $0 \mathrm{~h}$. Loss of mini slump flow was much smaller than that of channel flow. Their application in concrete mixes supports the trend of the channel flow, where the loss of slump flow was observed with all the waterreducing PCEs.

In the case of consistency-maintaining PCEs, LE16 and LF16 had rather lower initial channel flows, and then each of them had nearly doubled in $2 \mathrm{~h}$. Note that the values in the parentheses exceed the limit of the measuring range, which was $300-700 \mathrm{~mm}$ for the channel flow and $200-400 \mathrm{~mm}$ 
TABle 2: Performance test results.

\begin{tabular}{|c|c|c|c|c|c|c|}
\hline \multirow{2}{*}{ Label } & \multicolumn{3}{|c|}{ Mini slump flow of pastes (mm) } & \multicolumn{3}{|c|}{ Channel flow of mortars (mm) } \\
\hline & $0 \mathrm{~h}$ & $1 \mathrm{~h}$ & $2 \mathrm{~h}$ & $0 \mathrm{~h}$ & $1 \mathrm{~h}$ & $2 \mathrm{~h}$ \\
\hline LA12 & 400 & 390 & 360 & 635 & 555 & 450 \\
\hline LB12 & 290 & 260 & 260 & 645 & 430 & 350 \\
\hline $\mathrm{LC} 12$ & 360 & 350 & 340 & 640 & 610 & 470 \\
\hline LD16 & 280 & 300 & 310 & 520 & 360 & 320 \\
\hline LE16 & 260 & 370 & 400 & $(235)$ & 430 & 510 \\
\hline LF16 & 310 & $(440)$ & $(440)$ & 300 & 530 & 560 \\
\hline
\end{tabular}

TABLE 3: Rheological evaluation on the results of channel flow test.

\begin{tabular}{lcccc}
\hline Label & $C_{f}(\mathrm{~mm})$ & $C_{50}(\mathrm{~s})$ & $\tau_{y}(\mathrm{~Pa})$ & $\eta_{p}(\mathrm{~Pa} \cdot \mathrm{s})$ \\
\hline LA12 & 635 & 71 & 4.7 & 10.1 \\
LB12 & 645 & 62 & 4.4 & 5.58 \\
LC12 & 640 & 63 & 4.5 & 6.14 \\
LD16 & 520 & 36 & 11.8 & 3.72 \\
LE16 & 235 & 5 & 113 & 1.88 \\
LF16 & 300 & 7 & 67.4 & 2.07 \\
\hline
\end{tabular}

for mini slump flow as previously stated. The results of the mini slump flow corresponded with the increasing trend of fluidity and comparatively worse performance with LE16. LD16 showed a similar increase in the mini slump flow. However, its channel flow initially gave the highest values and it lost the fluidity within $1 \mathrm{~h}$.

Figure 7 comparatively shows the channel flow of the test mortars and the mini slump flow of the test pastes. Each linear line provides a correlation between two measurements. The correlations for the water-reducing PCEs again indicate poor sensitivity of the mini slump flow of the test pastes: it did not reveal the loss of fluidity. Even though the results of consistency-maintaining PCE samples are on a single line, the right line in the figure, the other PCE samples are far from the coherent trend. Therefore, it can be concluded that the mini slump flow of the test pastes does not represent the flow behavior of the corresponding mortar samples. The use of a test mortar, accompanied with the channel flow test, is believed to better explain the fluidity of concrete mix.

More investigation on the performance of PCE could be made by rheological interpretation. For the initial measurement of channel flow test, (4) to (6) calculated the rheological properties of the test mortars. Table 3 reports the calculated properties. Even though the water-reducing PCEs show the same fluidity $\left(C_{f} \approx 640 \mathrm{~mm}\right.$ and $\left.\tau_{y} \approx 4.5 \mathrm{~Pa}\right)$, the plastic viscosity is different: $10.1,5.58$, and $6.14 \mathrm{~Pa} \cdot \mathrm{s}$ for LA12, LB12, and LC12, respectively. A PCE having lower plastic viscosity is preferable for higher workability of concrete.

\section{Discussion}

The channel flow of a test mortar is also dependent on the characteristics of constituting materials such as cement and

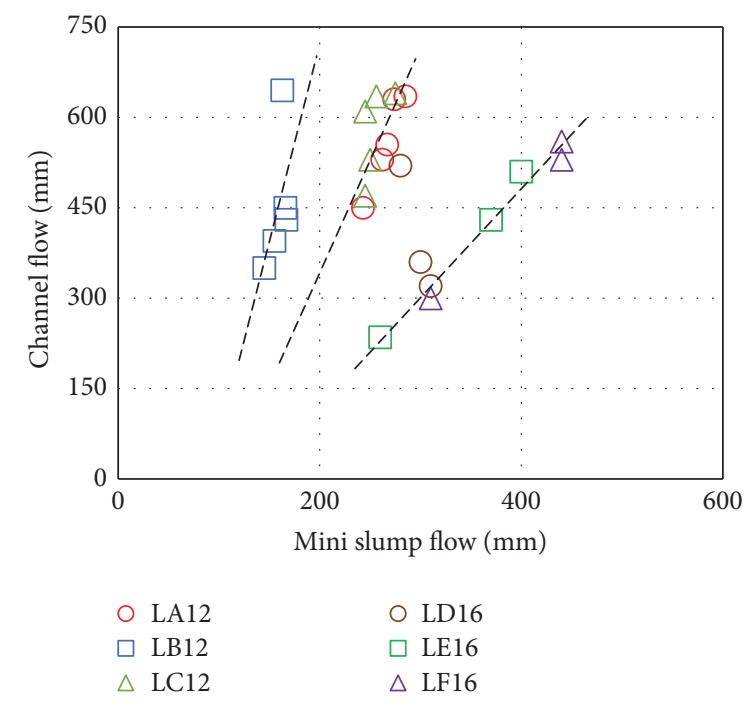

Figure 7: Comparison of channel flow and mini slump flow.

aggregates. Therefore, in order to compare the performance of PCEs, it is required to use the same materials for producing a test mortar. The variation according to the constituting materials is summarized here for future reference.

4.1. Batch of Portland Cement. Even if Portland cement, type I, is manufactured by an identical company, the mineral contents of cement can be different depending on the manufacturing time and process of production [15]. Table 4 shows the oxide composition of Portland cement from three different batches. The channel flows of LC12 using the three cements were in the range of $490 \pm 150 \mathrm{~mm}(517.7 \pm 5.91 \mathrm{in})$. The variation is approximately $\pm 31 \%$, which is beyond the resolution of the test $( \pm 4 \%)$ and then not an error factor.

4.2. Types of Binder. Blended cement is generally used to increase the fluidity [16] and the resistance against segregation. In this paper, a ternary binder (40\% cement A, 50\% ground-granulated blast furnace slag, and 10\% fly ash) was compared. The test mortar using the ternary binder was segregated with LC12, while the channel flow of $100 \%$ cement A-LC12 was $550 \mathrm{~mm}$ (21.7 in), as reported in Table 4. When the PCE dosage was decreased, the channel flow of $100 \%$ cement A-LC10 was $340 \mathrm{~mm}$ (13.4 in) and that using the ternary binder was $900 \mathrm{~mm}$ (35.4 in). In addition, the channel 
TABLE 4: Oxide composition of three batches.

\begin{tabular}{lcccccccccc}
\hline Label & $\mathrm{CaO}$ & $\mathrm{SiO}_{2}$ & $\mathrm{Al}_{2} \mathrm{O}_{3}$ & $\mathrm{Fe}_{2} \mathrm{O}_{3}$ & $\mathrm{SO}_{3}$ & $\mathrm{MgO}$ & $\mathrm{K}_{2} \mathrm{O}$ & $\mathrm{Na}_{2} \mathrm{O}$ & $\mathrm{TiO}_{2}$ & $\begin{array}{c}\mathrm{C}_{f} \text { for } \\
\mathrm{LC}_{2}\end{array}$ \\
\hline Cement A & $64.0 \%$ & $19.3 \%$ & $4.4 \%$ & $3.8 \%$ & $3.4 \%$ & $2.4 \%$ & $1.3 \%$ & $0.4 \%$ & $0.3 \%$ & $550 \mathrm{~mm}$ \\
Cement B & $64.6 \%$ & $18.0 \%$ & $4.8 \%$ & $3.3 \%$ & $3.7 \%$ & $3.6 \%$ & $1.1 \%$ & $0.2 \%$ & $0.3 \%$ & $640 \mathrm{~mm}$ \\
Cement C & $64.9 \%$ & $17.9 \%$ & $4.7 \%$ & $3.3 \%$ & $3.7 \%$ & $3.6 \%$ & $1.1 \%$ & $0.2 \%$ & $0.3 \%$ & $345 \mathrm{~mm}$ \\
\hline
\end{tabular}

TABle 5: The rheological properties of each mortar sample.

\begin{tabular}{lccc}
\hline Type & TSC/C & $\tau_{y}(\mathrm{~Pa})$ & $\eta_{p}(\mathrm{~Pa} \cdot \mathrm{s})$ \\
\hline \multirow{3}{*}{$\mathrm{BE}$} & $0.18 \%$ & 26.13 & 2.96 \\
& $0.21 \%$ & 19.03 & 3.18 \\
& $0.24 \%$ & 12.80 & 1.97 \\
\hline \multirow{2}{*}{ LC } & $0.27 \%$ & 6.27 & 1.28 \\
& $0.10 \%$ & 49.26 & 3.59 \\
& $0.12 \%$ & 9.32 & 3.53 \\
\hline
\end{tabular}

flow of LC10 increases up to $780 \mathrm{~mm}$ (30.7 in) when the waterto-cement ratio increased from 0.35 to 0.40 . Thus, the use of ternary binder is very effective in increasing the flow of cement-based materials.

4.3. Types of Sand. The standard sand is required for preparing a test mortar. The use of the other sand dramatically changes the channel flow even though its quality is "good" and its grading is comparable with the standard sand. A comparison was made with good-quality river sand. The average particle size and fineness modulus of river sand are $0.45 \mathrm{~mm}$ ( $0.0178 \mathrm{in}$ ) and 2.60, respectively, while those of standard sand were $0.77 \mathrm{~mm}$ (0.0303 in) and 2.51. Their difference was highlighted on the absorption rate: $0.79 \%$ versus $2.20 \%$ for the standard sand and the river sand, respectively. Adding $7.11 \mathrm{~g}(0.0157 \mathrm{lb} ; 0.79 \%$-absorption $)$ water to compensate the water adsorption of standard sand increased $10 \mathrm{~mm}$ channel flow of a test mortar, where the reference was $550 \mathrm{~mm}$ (21.7 in) for LC12, 100\% cement A. However, the mortar proportioned with river sand did not flow in spite of adding $19.8 \mathrm{~g}$ ( $0.0437 \mathrm{lb} ; 2.20 \%$-absorption) water. Inconsistency on the aggregate changes to a great extent the rheophysical state of a test mortar.

4.4. Dosage of PCE. The effect of PCE dosage can be compared with the results of channel flow test. For the mortar samples with a different dosage, the channel flow was firstly conducted. Table 5 shows the test results, where BE and LC are different-type PCEs. The dosage is reported in total solid content (TSC) per cement by mass. The rheograph, originally developed for SCC [17], was developed in Figure 8, where the PCE dosage is represented with the size of each symbol. A smaller dosage is depicted with a bigger circle symbol, which illustrates higher sensitivity to the dosage dependence. Adding more BE sample decreases both yields stress and

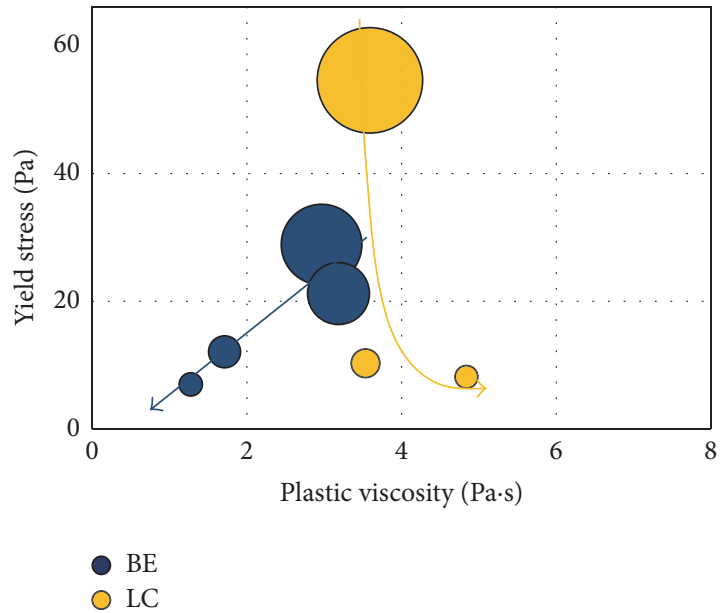

FIgURE 8: Rheograph showing the effect of PCE dosage.

plastic viscosity of a mix. However, LC sample dominantly decreases the yield stress first, and then its excessive dosage $(0.12 \%$ to $0.14 \%)$ increases the plastic viscosity, while its yield stress holds a constant value.

\section{Conclusions}

This paper has introduced the alpha test to evaluate the performance of PCE or HRWRA before a test concrete is mixed. The alpha test needs to be quickly finished and less loaded in terms of labor. The mini slump flow test for a test paste, currently widely used, has the limit on its sensitivity and representing the aggregate effect. The channel flow test with a test mortar is therefore proposed. The final spread and the time to get the stoppage of the spread are measures of the test, and a model converting them into rheological properties is also developed. The mix proportion of a test mortar is taken to represent the aggregate volume fraction of SCC. Future work will focus on ways to stack performance data of various PCEs or HRWRAs and quantitatively evaluate their performance grade.

\section{Competing Interests}

The authors declare that they have no competing interests.

\section{Acknowledgments}

This research was supported by a grant from Smart Civil Infrastructure Research Program funded by Ministry of 
Land, Infrastructure and Transport (MOLIT) of Korea government (13SCIPA02) and Korea Agency for Infrastructure Technology Advancement (KAIA).

\section{References}

[1] J. Plank, E. Sakai, C. W. Miao, C. Yu, and J. X. Hong, "Chemical admixtures-chemistry, applications and their impact on concrete microstructure and durability," Cement and Concrete Research, vol. 78, pp. 81-99, 2015.

[2] E. Sakai, A. Ishida, and A. Ohta, "New trends in the development of chemical admixtures in Japan," Journal of Advanced Concrete Technology, vol. 4, no. 2, pp. 211-223, 2006.

[3] S. Hanehara and K. Yamada, "Rheology and early age properties of cement systems," Cement and Concrete Research, vol. 38, no. 2, pp. 175-195, 2008.

[4] N. Tregger, L. Ferrara, and S. P. Shah, "Identifying viscosity of cement paste from mini-slump-flow test," ACI Materials Journal, vol. 105, no. 6, pp. 558-566, 2008.

[5] A. Bouvet, E. Ghorbel, and R. Bennacer, "The mini-conical slump flow test: analysis and numerical study," Cement and Concrete Research, vol. 40, no. 10, pp. 1517-1523, 2010.

[6] K. Yamada, T. Sugamata, and H. Nakanishi, "Fluidity performance evaluation of cement and superplasticizer," Journal of Advanced Concrete Technology, vol. 4, no. 2, pp. 241-249, 2006.

[7] J. H. Kim, H. J. Yim, and S. H. Kwon, "Quantitative measurement of the external and internal bleeding of conventional concrete and SCC," Cement and Concrete Composites, vol. 54, pp. 34-39, 2014.

[8] J. H. Lee, J. H. Kim, and M. K. Kim, "Fine aggregates size effect on rheological behavior of mortar," Journal of the Korea Academia-Industrial cooperation Society, vol. 16, no. 8, pp. 56365645, 2015.

[9] N. Roussel and P. Coussot, "'Fifty-cent rheometer' for yield stress measurements: from slump to spreading flow," Journal of Rheology, vol. 49, no. 3, pp. 705-718, 2005.

[10] J. H. Kim, H. R. Jang, and H. J. Yim, "Sensitivity and accuracy for rheological simulation of cement-based materials," Computers and Concrete, vol. 15, no. 6, pp. 903-919, 2015.

[11] T. Y. Shin, J. H. Lee, J. H. Kim, and M. K. Kim, "Correlation between channel-flow test results and rheological properties of freshly mixed mortar," Journal of the Korea Academia, vol. 17, no. 7, pp. 237-244, 2016 (Korean).

[12] P. Coussot and C. Ancey, "Rheophysical classification of concentrated suspensions and granular pastes," Physical Review E, vol. 59, no. 4, pp. 4445-4457, 1999.

[13] I. M. Krieger and T. J. Dougherty, "A mechanism for nonnewtonian flow in suspensions of rigid spheres," Journal of Rheology, vol. 3, no. 1, pp. 137-152, 1959.

[14] L. Struble and G.-K. Sun, "Viscosity of Portland cement paste as a function of concentration," Advanced Cement Based Materials, vol. 2, no. 2, pp. 62-69, 1995.

[15] R. P. Ferron, A. Gregori, Z. Sun, and S. P. Shah, "Rheological method to evaluate structural buildup in self-consolidating concrete cement pastes," ACI Materials Journal, vol. 104, no. 3, pp. 242-250, 2007.

[16] J. H. Kim, H. J. Yim, and R. D. Ferron, "In situ measurement of the rheological properties and agglomeration on cementitious pastes," Journal of Rheology, vol. 60, no. 4, pp. 695-704, 2016.

[17] O. H. Wallevik and J. E. Wallevik, "Rheology as a tool in concrete science: the use of rheographs and workability boxes," Cement and Concrete Research, vol. 41, no. 12, pp. 1279-1288, 2011. 

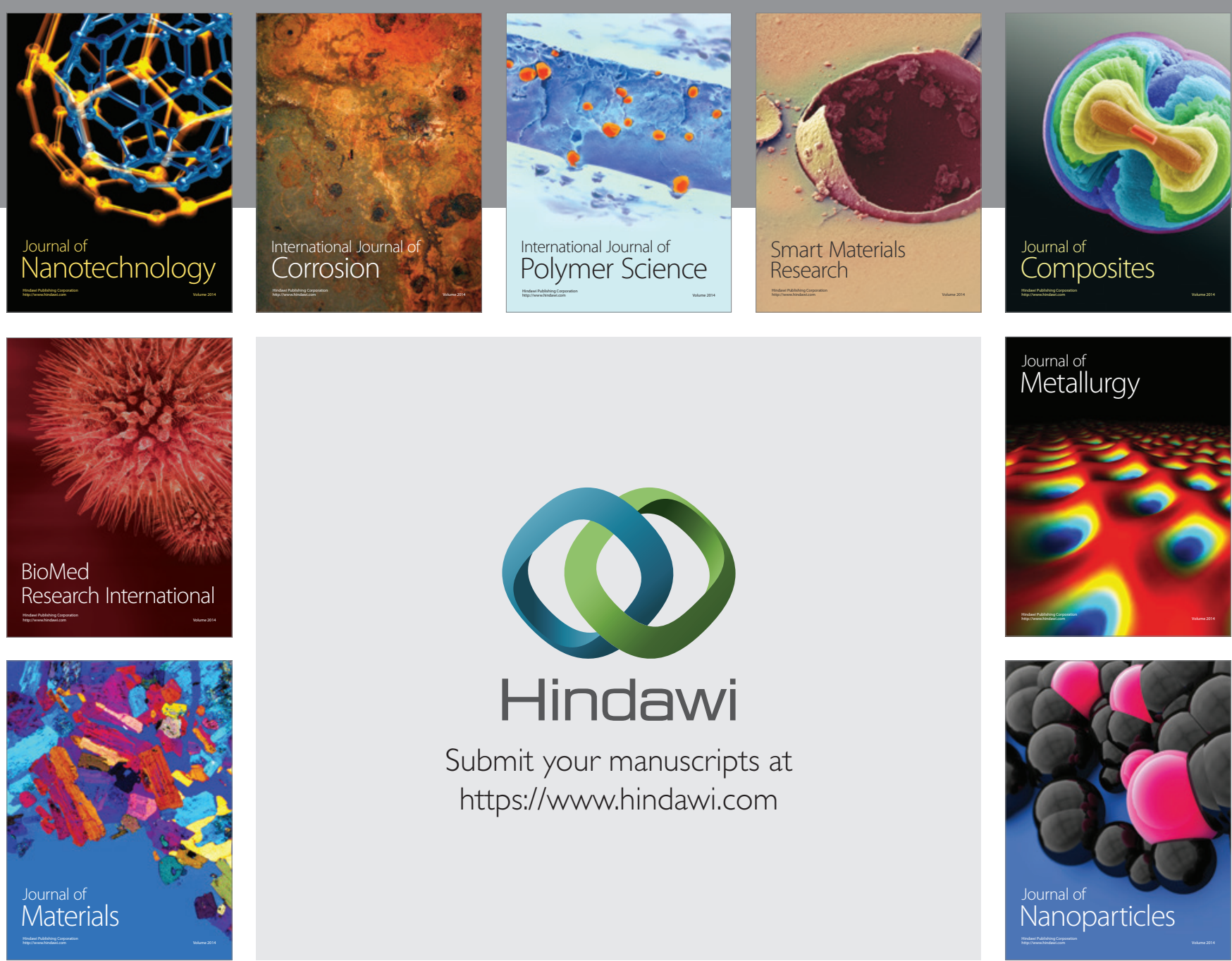

\section{Hindawi}

Submit your manuscripts at

https://www.hindawi.com

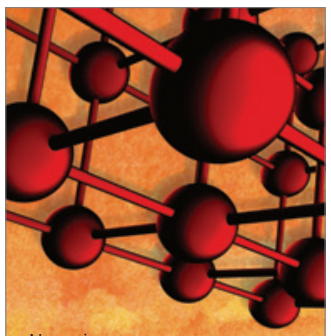

Materials Science and Engineering
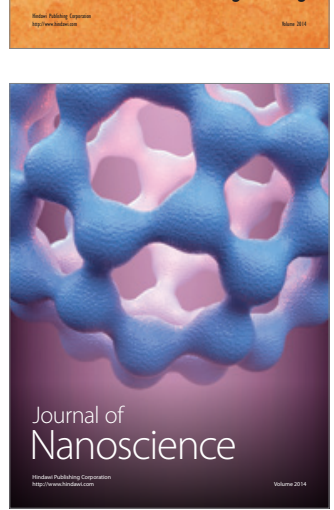
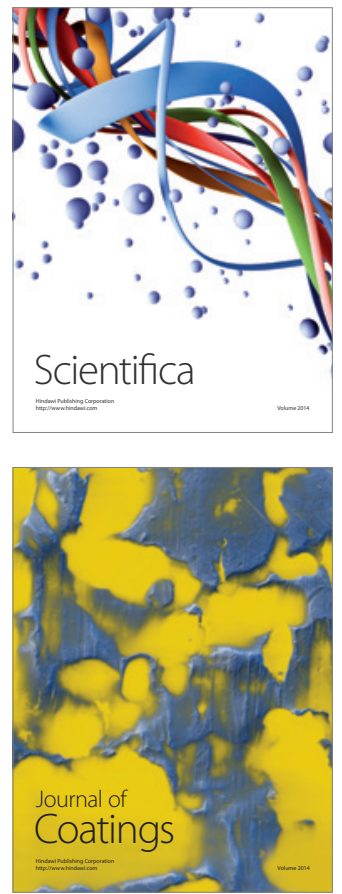
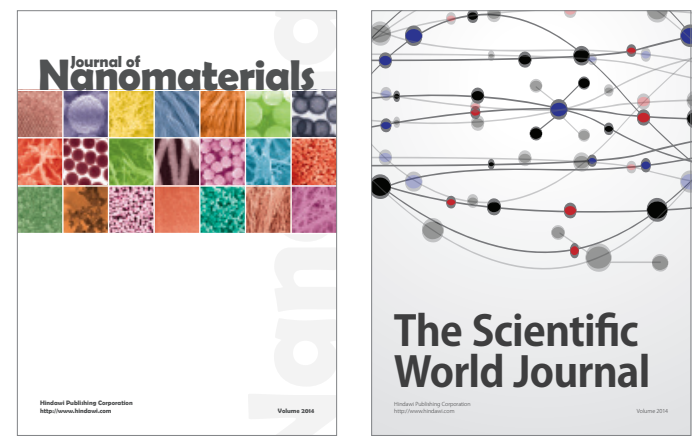

The Scientific World Journal
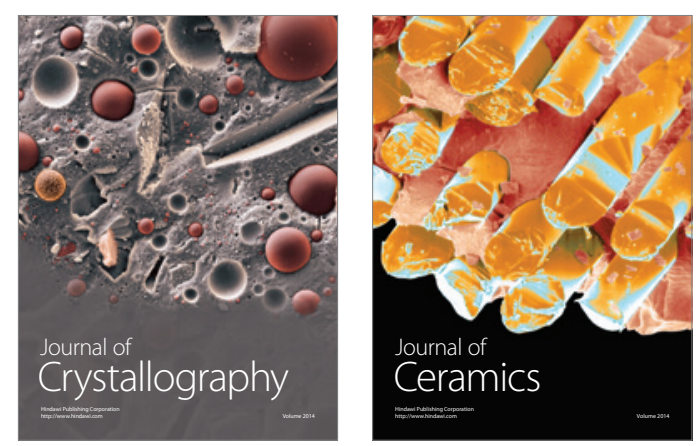
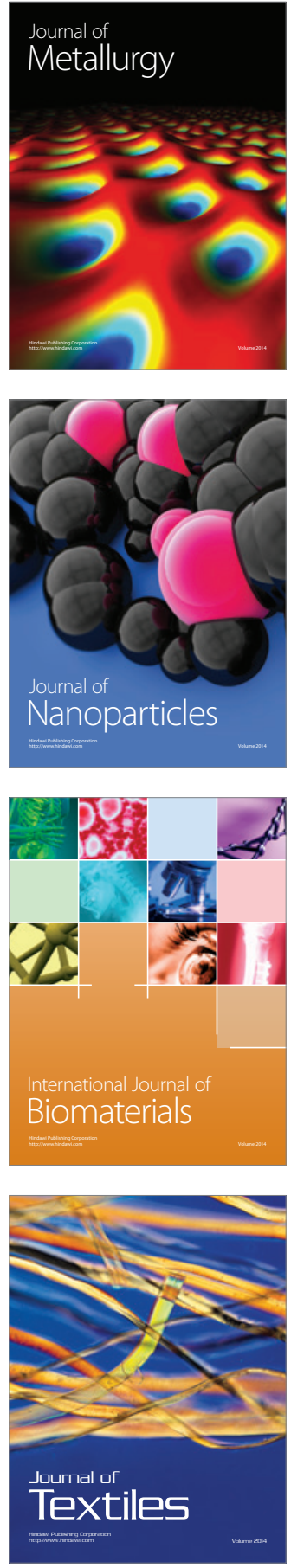